\title{
Apoio regional no estado do Rio de Janeiro, Brasil:
}

\author{
um relato de experiência
}

\author{
Roseni Pinheiro(a) \\ Ana Maria Auler Matheus Peres ${ }^{(b)}$ \\ Gabriel Velloso ${ }^{(c)}$ \\ Marcela de Souza Caldas(d)
}

Em 1986, ano da VIII Conferência Nacional de Saúde (CNS) - evento considerado um marco por garantir, pela primeira vez, a participação da população nas discussões e por ter as propostas geradas contempladas na Constituição Federal -, encontros paralelos à Conferência originaram a Comissão de Articulação de Municípios, que mais tarde se transformaria no Conselho Nacional de Secretarias Municipais de Saúde (Conasems). No mesmo ano, encontros regionais, realizados em municípios do estado do Rio de Janeiro (ERJ), resultaram na criação, em 1987, do Conselho de Secretarias Municipais de Saúde do Estado do Rio de Janeiro (Cosems RJ). Seu objetivo é apoiar tecnicamente as Secretarias Municipais de Saúde na condução de suas políticas de saúde, promovendo a articulação e a pactuação técnica e política dos interesses municipais, visando à defesa dos princípios e diretrizes do Sistema Único de Saúde (SUS).

O Cosems RJ busca, então, ser reconhecido como um órgão de defesa do SUS, como principal representação das secretarias e políticas municipais de saúde e como referência técnica e política para a intermediação dos interesses municipais no campo da saúde no ERJ'1. Uma de suas vias de ação é a Comissão Intergestores Bipartite (CIB) do Rio de Janeiro, que reúne os gestores municipais de saúde, equipe do Cosems RJ e a Secretaria Estadual de Saúde (SES) num espaço privilegiado de negociação e decisão quanto aos aspectos operacionais do SUS no estado, por meio da prática do planejamento integrado entre as esferas municipal e estadual ${ }^{2}$.

No artigo 198 da Constituição Federal de 1988, a ideia de um sistema de saúde a ser construído na forma de rede regionalizada e hierarquizada já se fazia presente ${ }^{3}$. Posteriormente, a Lei Federal n 8.080, de 1990 - Lei Orgânica da Saúde, que institucionalizou o Sistema Único de Saúde brasileiro e definiu a saúde como "direito fundamental do ser humano, devendo o Estado prover as condições indispensáveis ao seu pleno exercício" ${ }^{4}$ (p. 18055) - definiu, sob o princípio da descentralização, o papel central da regionalização da rede de serviços de saúde como diretriz do então novo sistema, o que foi reafirmado posteriormente pelas Normas Operacionais Básicas do SUS de 1996 (NOB 96) e pelo Pacto pela Saúde em 2006.

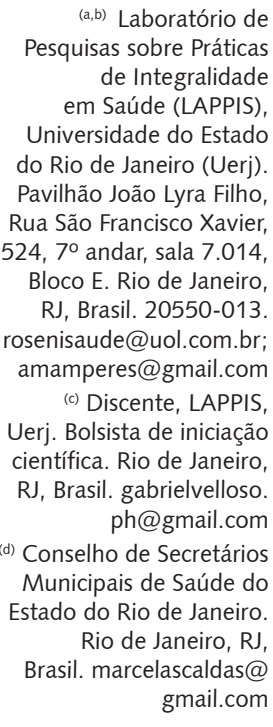


O princípio organizativo da regionalização priorizaria a autonomia entre os entes federados e a descentralização político-administrativa da gestão em saúde, almejando uma forma de gestão integrada e regionalizada, ampliando o acesso com maior qualidade e menor custo ${ }^{5}$. O processo de regionalização, que ganhou força em 2006 com o Pacto pela Saúde, possibilitou o desenvolvimento de estratégias e instrumentos voltados para a integração de serviços, agentes, instituições e práticas que reforçam a relação interfederativa entre as três esferas de governo, beneficiando a assistência, as vigilâncias, a formação e gestão de recursos humanos e a produção e alocação de tecnologias e insumos para a saúde .

Em junho de 2011, o Decreto Presidencial $n^{\circ} 7.508$ de 2011 trouxe mais avanços ao processo de regionalização do SUS no Brasil, pela regulamentação da Lei no 8080/1990: dentre outras medidas, normatizava e disciplinava o modo de articulação interfederativa, por meio dos Contratos Organizativos da Ação Pública de Saúde (Coap), estabelecendo as Comissões Intergestores Tripartite, Bipartite e Regionais; e estabeleceu as regiões de saúde como referência para a organização das Redes de Atenção à Saúde e para a transferência de recursos financeiros entre os entes federados ${ }^{7}$.

Em concordância com tais princípios e diretrizes do SUS, a adesão do ERJ ao Pacto pela Saúde em 2006 reafirmou o compromisso dos gestores com o fortalecimento da gestão regionalizada no Estado. Em 2007, a SES implantou o Programa Saúde na Área, que tinha como finalidade aprofundar conhecimento sobre a organização da prestação de serviços de saúde dos municípios e estabelecer uma relação mais próxima entre os gestores e a SES, reforçando ainda mais a regionalização e institucionalizando as regiões de saúde e seus colegiados ${ }^{8}$. Em 2009, foram realizados no Estado eventos como a Acolhida aos Secretários Municipais de Saúde, as Oficinas de Regionalização e os Seminários de Planejamento Regional. Com a redefinição das regiões de saúde em cada estado, ocorreu a criação dos Colegiados de Gestão Regional (CGR) - reuniões realizadas mensalmente nas regiões -, que, desde junho de 2011, são denominados Comissões Intergestores Regionais $(\mathrm{CIR})^{6}$. Atualmente, o ERJ é dividido em nove regiões de saúde, cada qual com suas dificuldades e especificidades quanto ao processo de regionalização: Baía de Ilha Grande, Baixada Litorânea, Centro Sul, Médio Paraíba, Metropolitana I, Metropolitana II, Noroeste, Norte e Serrana (Figura 1).

É nesse contexto que, em abril de 2012, o Cosems RJ, em parceria com o Laboratório de Pesquisas sobre Práticas de Integralidade em Saúde (Lappis) do Instituto de Medicina Social (IMS) da Universidade do Estado do Rio de Janeiro (Uerj), formulou e deu início ao Projeto Apoiadores Regionais do ERJ (PAR RJ), para apoiar institucionalmente os gestores municipais de saúde junto aos espaços de governança regional, objetivando fortalecer a gestão bipartite do SUS.

Desde a criação do Projeto Apoiadores Regionais em 2011, estratégias foram iniciadas, de modo a assegurar avanços em todo o ERJ e se configurando como ação exitosa, sobretudo em cada uma das nove regiões de saúde, na direção de produzir um sistema de saúde mais integrado e eficiente. É considerando a importância de compartilhar experiências de apoio que apresentaremos alguns aspectos desse trabalho, ainda em curso, mas com potência de inovação para o estado do Rio de Janeiro.

\section{Apoio regional: construindo novos modos de fazer a gestão regionalizada em saúde}

O apoio, originalmente proposto por Campos $^{9}$, tem como propósito assegurar retaguarda especializada a equipes e profissionais encarregados da atenção a problemas de saúde.

Apoio matricial e a equipe de referência são metodologias de trabalho, modo para se realizar a gestão da atenção em saúde, mas são, ao mesmo tempo, arranjos organizacionais que buscam diminuir a fragmentação imposta ao processo de trabalho decorrente da especialização crescente em quase todas as áreas de conhecimento. ${ }^{10}$ (p. 402) 


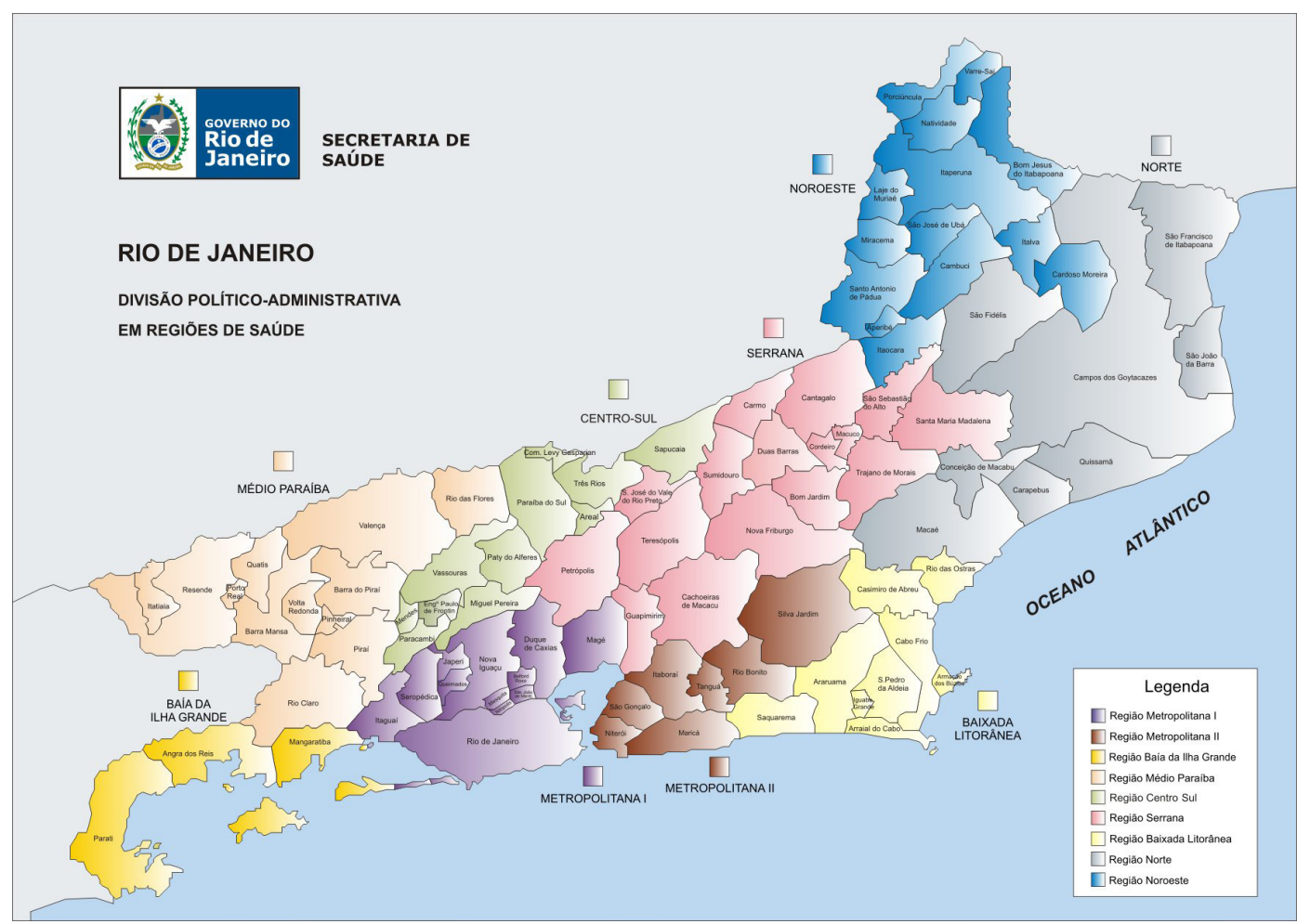

Figura 1. As nove regiões de saúde do estado do Rio de Janeiro (SES RJ, 2013).

Embasado nas ideias de Campos $^{9}$, o Cosems RJ construiu um modelo de apoio para os gestores municipais de saúde, tanto para a gestão em seus próprios municípios quanto para fortalecer as relações interfederativas que se impõem no espaço de governança regional. O apoio configura-se, dessa forma, também como estratégia para instrumentalização do gestor municipal, contribuindo para a qualificação da sua atuação nos espaços de interlocução bipartite.

Sobre a função de apoio, o coordenador da PNH, Gustavo Nunes de Oliveira ${ }^{11}$, no I Fórum da Atenção Básica, afirmou que:

[...] a atualização das relações interfederativas, com o decreto 7508, pode favorecer uma capacidade institucional menos suscetível às dificuldades. $\mathrm{O}$ apoiador deve ter capacidade de formar espaços coletivos de gestão para se pensar a rede e pensar o SUS. [...] o apoio institucional como estratégia de cogestão, ampliando a conversa entre gestores, trabalhando com a valorização do trabalho e do trabalhador do SUS e incluindo o usuário.

Com relação aos espaços de atuação dos apoiadores regionais do Cosems, segundo Gustavo Nunes de Oliveira ${ }^{12}$, " $[\ldots]$ os colegiados de gestão regional (CGR) precisam ser apoiados e empoderados para que os problemas locorregionais sejam discutidos e solucionados em mesas de negociação e de pactuação regional efetivas" (p. 26).

Sendo assim, propõe-se aqui uma nova visão de apoio, aplicando os conceitos propostos e ideias discutidas acerca do apoio institucional por $\operatorname{Campos}^{9,10}$ e por Oliveira ${ }^{11,12} \mathrm{em}$ âmbito regional. Dessa forma, entende-se que o apoio regional é uma estratégia de cogestão em municípios de situações sociosanitárias semelhantes, que se dá nos espaços de pactuação regional - atualmente, as CIR. 
Essa estratégia consiste no trabalho, dentro de espaços coletivos de gestão, de ampliar a discussão sobre as carências da saúde pública de cada município para um nível regional, onde suas soluções possam ser entendidas e buscadas como metas comuns à integralidade dos municípios envolvidos e dos outros entes federados, utilizando para isso vantagens inerentes a eles e avanços adquiridos individualmente. Os mecanismos de trabalho dessa estratégia de apoio regional incluem o acompanhamento e a instrumentalização do gestor municipal, a criação de ferramentas que permitam a quantificação, comparação e projeção de resultados positivos para a saúde da região e a existência de um ou mais agentes que promovam e intermedeiem a estratégia de apoio.

\section{Metodologia: experiência e experienciação}

O presente trabalho propôs-se a analisar a experiência do Programa Apoiadores Regionais do Rio de Janeiro e seus efeitos sobre os diferentes espaços de governança trabalhados. Para Pinheiro e Ceccim ${ }^{13}$, a experiência não deve ser vista como um estudo de caso que distinga o certo do errado, como o ato de experimentar, que exige controle, ou como a aquisição passiva de conhecimento. Por isso, foge-se aqui tanto de uma posição arbitrária, acerca do projeto, quanto de uma visão cientificista e estática, no que compete à própria análise e aos resultados, respectivamente.

$\mathrm{Na}$ mesma obra, os autores descrevem a experiência, segundo Foucault, como experiência de si e que tira o sujeito de si para migrar, recriar e potencializar vivências. Prosseguem ainda sobre o ato de analisar uma experiência:

Analisar experiências, então, significa conceber o cotidiano como o lugar onde as ações desenvolvidas, sejam elas simbólicas ou práticas, produzem sentidos e se configuram como práxis. Como uma noção constituinte da experienciação, seu território, o cotidiano, se ergue como fonte construtivista que implica processos de interação. ${ }^{13}$ (p. 17)

Dessa forma, entende-se que a visão de experiência a ser trabalhada é do projeto, em si, como um processo que, desde seu princípio, causa mudanças em seus espaços cotidianos. Para realizar a análise dessa experiência, é necessária, contudo, uma sistematização das experiências, como propõe Holliday ${ }^{14}$ :

A sistematização é aquela interpretação crítica de uma ou várias experiências que, a partir de seu ordenamento e reconstrução, descobre ou explicita a lógica do processo vivido, os fatores que intervieram no dito processo, como se relacionam entre si e porque o fizeram desse modo. (p. 24)

Ainda sobre essa sistematização, o autor propõe outras características importantes e complementares ao conceito, como sua capacidade de objetivar o vivido, de ordenar conhecimentos e percepções dispersas e de atentar às interpretações, além dos acontecimentos, comportamentos e evoluções ${ }^{14}$. Apropriando-se desses conceitos, a metodologia aplicada a este trabalho compreende uma análise que contemple a caracterização do projeto quando de sua proposição, sua evolução até o presente momento, os resultados elementares e os abstratos e a interpretação crítica das relações estabelecidas ao longo de todo o processo.

\section{As nove regiões de saúde do estado do Rio de Janeiro: os lugares das experiências}

Baía de Ilha Grande: caracterizada inicialmente por ser a menor região do ERJ em número de municípios e população - respectivamente, três e menos de trezentos mil pessoas ${ }^{15}$-, a Baía de Ilha Grande é formada por Angra dos Reis, Mangaratiba e Paraty. 
Baixada Litorânea: formada por nove municípios e uma população de cerca de seiscentos e oitenta mil habitantes ${ }^{15}$, a região é formada por Araruama, Armação de Búzios, Arraial do Cabo, Cabo Frio, Casimiro de Abreu, Iguaba Grande, Rio das Ostras, São Pedro d'Aldeia e Saquarema. A Baixada Litorânea tem como destaque de seu processo de regionalização o estabelecimento de Centrais de Regulação Municipal nos municípios de Búzios e Arraial do Cabo ${ }^{8}$.

Médio Paraíba: em 1998, foi formado na região o Consórcio Intermunicipal de Saúde do Médio Paraíba (Cismepa) - consórcio público de direito público que promove capacitação de profissionais, acompanhamento técnico das secretarias de saúde, desenvolvimento de projetos de saúde pública e outras ações ${ }^{1}$. Região formada por 12 municípios e mais de oitocentos e cinquenta mil habitantes ${ }^{15}$, Médio Paraíba foi também a primeira região do ERJ a demonstrar interesse e assinar o Coap. Barra do Piraí, Barra Mansa, Itatiaia, Pinheral, Piraí, Porto Real, Quatis, Resende, Rio Claro, Rio das Flores, Valença e Volta Redonda são os municípios que integram a região que contará, até 2014, com um hospital regional para atender moradores.

Centro Sul: composta por 11 municípios e uma população de cerca de trezentos e vinte mil habitantes ${ }^{15}$, a região Centro Sul reúne os municípios de Areal, Comendador Levy Gasparian, Engenheiro Paulo de Frontin, Mendes, Miguel Pereira, Paracambi, Paraíba do Sul, Paty do Alferes, Sapucaia, Três Rios e Vassouras.

Metropolitana I: formada por 12 municípios, que concentram mais de 60\% da população fluminense $^{15}$, a região Metropolitana I é composta pelos municípios de Belford Roxo, Duque de Caxias, Itaguaí, Japeri, Magé, Mesquita, Nilópolis, Nova Iguaçu, Queimados, Rio de Janeiro, São João de Meriti e Seropédica. Atualmente, a região tem como seu principal obstáculo e tema de discussão o déficit de leitos.

Metropolitana II: com uma população de cerca de 2 milhões de habitantes ${ }^{15}$, a região é formada por sete municípios: Itaboraí, Maricá, Niterói, Rio Bonito, São Gonçalo, Silva Jardim e Tanguá. O processo de regionalização da Metropolitana II se iniciou antes mesmo do estabelecimento do CGR, durante a discussão para implantação de um Serviço de Atendimento Móvel de Urgência (Samu) regional pela criação de uma Comissão das Regiões Metropolitanas. Desde então, a região é marcada pela integração entre os municípios, que, dentre outras ações, articularam a construção da Unidade de Pronto-Atendimento (UPA) de Rio Bonito, que beneficia também o município vizinho de Tanguá. Outro destaque é o atual papel da CIR para ajudar a solucionar os déficits dos municípios com relação às cirurgias e aos procedimentos de média e alta complexidade ${ }^{8}$.

Noroeste: a segunda maior região de saúde do ERJ em número de municípios, 14, a Noroeste possui quase trezentos e cinquenta mil habitantes, dos quais a maioria - cem mil mil - está concentrada em um município-polo - Itaperuna ${ }^{15}$. Dessa forma, a falta de recursos financeiros e humanos próprios nos outros 13 municípios menores - Aperibé, Bom Jesus de Itabapoana, Cambuci, Cardoso Moreira, Italva, Itaocara, Itaperuna, Laje do Muriaé, Miracema, Natividade, Porciúncula, Santo Antônio de Pádua, São José de Ubá e Varre-Sai -, somada à grande distância entre a região e a capital fluminense, configura uma situação desfavorável ao processo de regionalização, que tem como uma das metas distribuir melhor a grande demanda que é absorvida pelo município-polo.

Norte: apesar das grandes diferenças econômicas entre seus municípios, oriundas dos recursos gerados pela atividade do setor produtor de petróleo, os gestores da região Norte foram capazes de estabelecer relações de forte integração. Com mais de oitocentos e trinta mil habitantes ${ }^{15}$, os oito municípios da região - Campos dos Goytacazes, Carapebus, Conceição de Macabu, Macaé, Quissamã, São Fidélis, São Francisco de Itabapoana e São João da Barra - enfrentam ainda um crescimento populacional associado a uma população flutuante, o que gera problemas sociais e, principalmente, dificulta o planejamento da saúde pública na região.

Serrana: com o maior número de municípios inscritos, a região Serrana é a terceira mais populosa do ERJ, com mais de novecentos mil habitantes ${ }^{15}$. Ela é formada por 16 municípios: Bom Jardim, Cachoeira de Macacu, Cantagalo, Carmo, Cordeiro, Duas Barras, Guapimirim, Macuco, Nova Friburgo, Petrópolis, Santa Maria Madalena, São José do Vale do Rio Preto, São Sebastião do Alto, Sumidouro, Teresópolis e Trajano de Moraes. Afetada pela tragédia climática das fortes chuvas de janeiro de 2011, a região enfrentou dificuldades financeiras e estruturais na saúde e em todas as outras áreas, 
investindo na regionalização para se reerguer, o que resultou em iniciativas como a pactuação da Rede de Urgência e Emergência e a implantação de um Samu regional ${ }^{8}$.

\section{Questões norteadoras da experiência do Projeto Apoiadores Regionais}

Entendendo as dificuldades em comum de cada região e, ainda, as especificidades que caracterizam cada uma delas, o Cosems RJ iniciou, em abril de 2012, o Projeto Apoiadores Regionais no ERJ.

Realizado em parceria com o Laboratório de Pesquisas sobre Práticas de Integralidade em Saúde da Uerj, o projeto visa promover apoio institucional regionalizado aos gestores municipais de saúde do ERJ em suas relações com o governo estadual, demais municípios e nas relações interfederativas da região.

Foram selecionados profissionais para garantir o apoio presencial e à distância aos gestores municipais nos espaços de governança regional - os apoiadores regionais -, que participam desses espaços sem ter direito a voto. Eles têm como funções: participar na CIB-RJ e nas CIR; participar de eventos relacionados à elaboração do Coap; apoiar diretamente as Secretarias Municipais de Saúde das regiões; assessorar a diretoria do Cosems RJ; elaborar e encaminhar agendas semanais; realizar reuniões temáticas quando solicitadas; elaborar o Diagnóstico da Região; e elaborar e atualizar os instrumentos do apoio, dentre outras atribuições.

Em seu primeiro ano de execução, o PAR RJ esteve presente em todas as regiões de saúde do ERJ por meio de quatro apoiadores regionais, contribuindo direta e indiretamente para os avanços do SUS em cada uma delas. Embora seus resultados ainda não sejam quantificáveis, é possível apresentar alguns dos produtos do PAR RJ que contribuíram para seu desenvolvimento e divulgação.

Fórum online: apresentado no primeiro encontro de 2013 do PAR RJ, o fórum on-line é uma ferramenta virtual que tem como objetivo fornecer orientações, disponibilizar documentos importantes e aperfeiçoar a comunicação entre o Cosems RJ, gestores e técnicos da saúde pública fluminense. O fórum pode ser acessado por gestores municipais, apoiadores regionais e técnicos do Cosems RJ por meio do sítio eletrônico do Conselho e é dividido em fóruns regionais, que permitem a interação dos gestores e apoiadores de cada região, e um fórum geral, onde são debatidos temas em comum entre duas ou mais regiões ${ }^{1}$. Pretende-se que os fóruns se configurem como espaços para a discussão de temas relacionados aos interesses regionais para o fortalecimento do SUS e discussões provenientes das Câmaras Técnicas, dos Grupos de Trabalho e das CIR. O fórum on-line possibilita, ainda, o compartilhamento de documentos entre os gestores e apoiadores de cada região, além da publicação de avisos nos âmbitos regionais ou estadual.

Planilha agenda dos gestores municipais: também vinculada ao sítio eletrônico do Cosems RJ e apresentada na primeira reunião de 2013 do PAR RJ, a planilha agenda dos gestores municipais é um instrumento institucional que visa à orientação dos apoiadores regionais quanto à agenda quadrimestral dos municípios, ao acompanhamento dos apoiadores pela coordenação do projeto e à formulação de um retrato da gestão por meio de um consolidado de dados da gestão municipal ${ }^{1}$. Devendo ser preenchida pelos apoiadores regionais após cada fim de quadrimestre, a planilha contém informações gerais sobre os instrumentos de gestão (Coap, Relatório de Gestão, Plano Municipal de Saúde e outros) e informações quadrimestrais, que compõem as agendas municipais de ações, campanhas, eventos e metas. Projeta-se que a planilha será um mecanismo eficiente e atualizado de supervisão dos apoiadores regionais e gestores municipais e importante fonte para futuras pesquisas quantitativas sobre os resultados do PAR RJ.

Contudo, o resultado mais visível do Projeto no ERJ é a capilarização do Cosems RJ nas regiões. A entidade, que inicialmente era apenas um colegiado deliberativo, hoje conta com uma série de técnicos, como os apoiadores regionais, que interagem diretamente com os municípios e regiões de saúde, buscando soluções para os desafios de gestão que são encontrados. Dessa forma, o Cosems RJ agora mantém contato mais direto e permanente com as regiões, conhecendo-as e sendo capaz de responder à sua demanda com apoio regional e técnico. 


\section{Conclusões}

Desde a VIII Conferência Nacional de Saúde de 1986 e durante todo o processo de construção do Sistema Único de Saúde no Brasil - que se estende até a atualidade -, o princípio da regionalização foi denominado, apresentado, debatido e proposto. Ele estava presente na já citada CNS, assim como em todas as que se seguiram. Foi também conteúdo indispensável à Seção da Saúde da Constituição Federal de 1988, à Lei no 8080/90, às Normas Operacionais Básicas do SUS, ao Pacto pela Saúde, ao Contrato Organizativo da Ação Pública da Saúde, ao Decreto Presidencial n. 7508/11 e a tantas outras leis, normas operacionais, pactos, contratos, decretos, resoluções e programas. Em muitos estados brasileiros, contudo, o processo de regionalização foi lentamente posto em prática.

No estado do Rio de Janeiro, apenas em 2007, foram institucionalizadas as regiões de saúde e seus Colegiados de Gestão Regional - futuras Comissões Intergestores Regionais -, por meio do programa Saúde na Área, da Secretaria de Estado de Saúde. Apesar do lento início do processo de regionalização, ações conjuntas da SES, Secretarias Municipais de Saúde e Cosems RJ foram realizadas no sentido de sua aceleração e do fortalecimento do SUS no ERJ. Uma das iniciativas mais relevantes do Cosems RJ nesse processo foi o Projeto Apoiadores Regionais, iniciado em abril de 2012.

Contando com a experiência e capacitação de cada apoiador regional, o projeto produziu avanços em diferentes níveis em cada região de saúde do ERJ. O PAR RJ gerou também avanços coletivos no tocante à produção de novos instrumentos de comunicação, orientação e coleta de dados, representados pelo fórum on-line e pela planilha agenda. Essas ferramentas poderão, em futuro próximo, fornecer novos dados para análises qualitativas e quantitativas acerca do projeto e, principalmente, do próprio processo de regionalização do ERJ. Sobretudo, permitiu ao Cosems RJ um avanço na relação com os gestores e gestões de saúde de todo o Estado, fazendo-se presente, principalmente, nos novos espaços de governança regional.

Com a participação mais direta do Cosems RJ e a orientação pelo Laboratório de Práticas sobre Integralidade em Saúde da Uerj, o Projeto Apoiadores Regionais avança para um segundo estágio. Agora, com um número maior de apoiadores regionais - um a cada duas regiões -, o projeto é capaz de dar melhor assistência às regiões, integrando-as internamente pela articulação regional e, externamente, pela troca de informações entre os apoiadores.

Com as novas ferramentas do projeto, toda essa integração será facilitada, permitindo o melhor enfrentamento dos principais desafios dos gestores fluminenses. A expectativa é que o projeto, portanto, contribua cada vez mais para o fortalecimento de um SUS que ponha em prática seus princípios organizativos - em especial, a regionalização - para assim poder garantir seus princípios doutrinários.

\section{Colaboradores}

Os autores trabalharam juntos em todas as etapas de produção do manuscrito. 


\section{Referências}

1. Conselho de Secretarias Municipais de Saúde do Estado do Rio de Janeiro [acesso 2013 Mar 23]. Disponível em: http://www.cosemsrj.org.br/index.html

2. Comissão Intergestores Bipartite do Rio de Janeiro [acesso 2013 Mar 26]. Disponível em: http://www.cib.rj.gov.br/conheca-a-cib-rj/2374-historico.html

3 Constituição (1988). Constituição da República Federativa do Brasil. Brasília (DF): Senado; 1988.

4. Ministério da Saúde. Lei no 8.080, de 19 de Setembro de 1990. Dispõe sobre as condições para a promoção, proteção e recuperação da saúde, a organização e o funcionamento dos serviços correspondentes e dá outras providências. Diário Oficial da União. 19 Set 1990.

5. Ministério da Saúde. Portaria GM/MS n 2.203, de 5 de novembro de 1996. Aprova a Norma Operacional Básica do Sistema Único de Saúde, NOB-SUS 01/96. Diário Oficial da União. 6 Nov 1996.

6. Conselhos de Secretaria Municipais de Saúde do Estado do Rio de Janeiro. Regionalização no Rio de Janeiro garante avanços na saúde pública dos municípios fluminenses. Cosems RJ. 2012; (16):10-1.

7. Castro L, Oliveira R. O Decreto 7.508/2011: desafios e oportunidades. Cosems RJ. 2011; (7):26-33.

8. Secretaria de Estado de Saúde do Rio de Janeiro [acesso 2013 Mar 23]. Disponível em: http://www.saude.rj.gov.br

9. Campos GWS. Equipes de referência e apoio especializado matricial: uma proposta de reorganização do trabalho em saúde. Cienc Saude Colet. 1999; 4(2):393-404.

10. Campos GWS, Domitti AC. Apoio matricial e equipe de referência: uma metodologia para gestão do trabalho interdisciplinar em saúde. Cad Saude Publica. 2007; 23(2):399-407.

11. Oliveira GN. Palestra. In: Anais do $1^{\circ}$ Fórum Nacional de Atenção Básica; 2012; Brasília. Brasília (DF); 2012 [acesso 2013 Mar 23]. Disponível em: http://portal.saude.gov. $\mathrm{br} /$ portal/saude/visualizar_texto.cfm?idtxt=39553

12. Oliveira GN. Devir apoiador: uma cartografia da função apoio [tese]. Campinas: Universidade Estadual de Campinas; 2011

13. Pinheiro R, Ceccim RB. Experienciação, formação, cuidado e conhecimento em saúde. In: Pinheiro R, Ceccim RB, Mattos RA, organizadores. Ensinar saúde: a integralidade e o SUS nos cursos de graduação na área da saúde. Rio de Janeiro: Cepesc, IMS, UERJ, Abrasco; 2011. p. 13-35.

14. Holliday OJ. Para sistematizar experiências. Brasília (DF): MMA; 2008.

15. Instituto Brasileiro de Geografia e Estatística. XII Censo Demográfico. Rio de Janeiro: IBGE; 2010 [acesso 2013 Mar 23]. Disponível em: http://www.censo2010.ibge.gov.br/ sinopse/index.php?uf $=33 \&$ dados $=1$ 
No contexto do processo de regionalização do Sistema Único de Saúde (SUS) surgiram iniciativas para promover as regiões de saúde e seus municípios circunscritos por meio do apoio, que busca reformular os tradicionais mecanismos de gestão. Propõe-se o conceito de apoio regional, que se iniciou, na cidade do Rio de Janeiro, Brasil, com o objeto deste trabalho: o Projeto Apoiadores Regionais, criado pelo Conselho de Secretários Municipais de Saúde do Estado do Rio de Janeiro (Cosems-RJ) em parceria com o Laboratório de Pesquisas sobre Práticas de Integralidade em Saúde, Universidade do Estado do Rio de Janeiro (Lappis-Uerj). Na análise do projeto, utilizou-se a sistematização da experiência, gerando uma interpretação crítica. Entende-se que houve importante ampliação do papel do Cosems-RJ nos espaços de governança regional, destacando-se os novos instrumentos de gestão criados. Conclui-se com a visão de longo prazo acerca do projeto e suas possíveis consequências para o SUS.

Palavras-chave: Apoio institucional. Gestão em Saúde. Política de Saúde. Regionalização. Sistema Único de Saúde.

\section{The regional support in the state of Rio de Janeiro, Brazil: an experience report}

In the context of the Brazilian Health System (SUS) regionalization process, some initiatives have been promoting the health regions and their municipalities through the support, which seeks to reformulate the traditional health management mechanisms. Therefore, it is proposed the concept of rregional support, whose field is the interfederative relations of health regions, started in Rio de Janeiro, as object of this work: the Regional Supporters Project, created by Conselho de Secretários Municipais de Saúde do Estado do Rio de Janeiro (Cosems-RJ) in partnership with Laboratório de Pesquisas sobre Práticas de Integralidade em Saúde, Universidade do Estado do Rio de Janeiro (Lappis-Uerj). To analyze this project, the experience systematization was used, in order to create a critical interpretation of the experiences. It is explained, then, that there was significant expansion of the Cosems-RJ role in regional governance spaces, and the new management tools are presented. Finally, this work concludes with a long-term vision of the project and its possible consequences for the Brazilian health system.

Keywords: Health management. Health policy. Institutional support. Regional Health planning. Brazilian Health System.

\section{El apoyo regional en el estado del Rio de Janeiro, Brasil: un relato de experiencia}

En el proceso de regionalización del Sistema Brasileño de Salud (SUS), iniciativas promoven las regiones de salud y sus municipios por medio del apoyo, que busca reformular mecanismos de gestión tradicionales. Se propone el concepto de apoyo regional, cuyo campo de acción son las relaciones interfederativas de las regiones de salud y comenzó, en Rio de Janeiro, con el Proyecto Apoyadores Regionales, creado por el Conselho de Secretários Municipais de Saúde do Estado do Rio de Janeiro (Cosems-RJ) y el Laboratório de Pesquisas sobre Práticas de Integralidade em Saúde, Universidade do Estado do Rio de Janeiro (Lappis-Uerj). Para analisar el proyecto, se apropió de la sistematización de la experiencia, para generar una interpretación crítica. Se entiende que hubo expansión significativa de la función del Cosems-RJ en los espacios de gobernanza regional y fueron destacadas las nuevas herramientas de gestión creadas. Se concluye con uma visión a largo plazo acerca del proyecto y sus posibles consecuencias para el SUS.

Palabras clave: Apoyo institucional. Gestión en Salud. Política de Salud. Regionalización. Sistema Brasileño de Salud. 
